\title{
La sexología frente al cuerpo de las biomujeres: un análisis crítico a partir de dos programas televisivos
}

\section{Daniel Fernández Fernández ${ }^{1}$}

\section{Resumen}

El presente artículo analiza el tratamiento de la sexualidad de las biomujeres por parte del discurso sexológico, tomando como referente dos programas televisivos en los que interviene el criterio de un profesional de dicho campo. Contrario a otras producciones televisivas con enfoque sexológico en las que prima una perspectiva "orgasmológica", la visión que presentan dichos programas conlleva un acento marcadamente mórbido y profiláctico, dando como resultado una corporalidad femenina deserotizada. Concomitantemente, la sexualidad femenina deviene en estos programas un objeto de codificación binaria, aspecto que ratifica los patrones coercitivos del contrato heterosexual.

\section{Palabras clave}

Sexualidad; biopoder; misoginia; heteronormatividad; morbilidad

\section{Abstract}

This article analyzes the treatment of sexuality of biowomen by the sexological discourse, taking as reference two television programs that involved the criterion of a professional in that field. Unlike other television productions with sexological approach in which prevails an "orgasmologic" perspective, the vision of these programs entails a morbid and prophylactic emphasis, resulting in an uneroticized female corporality. Therefore, female sexuality in these programs becomes an object of binary encoding, which confirms the coercive patterns of heterosexual contract.

\section{Key words}

Sexuality; biopower; misogyny; heteronormativity; morbility

1 Costarricense. Licenciando de Psicología por Universidad de Costa Rica (UCR). Investigador del Instituto de Investigación en Educación (INIE) y Docente de la Escuela de Psicología, ambos en la UCR y del Bachillerato en Gestión del Desarrollo Sostenible con Equidad de Género de la Universidad Nacional. Correo electrónico: danielfernand@gmail.com 


\section{Resumo}

O presente artigo analisa a abordagem que se faz da sexualidade das biomulheres no discurso sexológico de dois programas de televisão, nos quais intervém o critério dum profissional neste campo. Ao contrário de outras produções televisivas com enfoque sexológico onde prevalece uma perspectiva "orgasmológica", a visão que apresentam tais programas acarreta um acento notavelmente mórbido e profiláctico, produzindo assim uma corporalidade deserotizada. Neste sentido, a sexualidade feminina torna-se nestes programas um objeto de codificação binária, aspecto que ratifica as pautas de coerção do contrato heterossexual.

\section{Palavras chave}

Sexualidade; biopoder; misoginia; heteronormatividade; mobilidade

\section{Introducción}

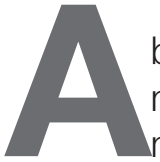

bordar la sexualidad desde una perspectiva crítica implica discernir qué lugar ocupa dentro de las discursividades contemporáneas. Placer y deseo constituyen centros privilegiados para un control biopolítico de la subjetividad, sobre los cuales se ha venido delineando lo que podríamos llamar sus contornos, aquellos que hacen factible fijar sus extensiones y sus límites, en la medida en que continuamente se demarca el espacio consentido para sus oscilaciones, dictando además las vías privilegiadas para signar sus posibilidades de existencia.

En este artículo se busca abordar la forma en que la sexualidad es asida por el discurso médico sexológico, atendiendo para ello la forma en que la sexualidad de las biomujeres ${ }^{2}$ es concebida en el programa televisivo En el punto: de la ciencia al sexo, del Sistema Nacional de Radio y Televisión de Costa Rica (SINART), dirigido por el sexólogo costarricense Mauro Fernández, así como en una sección del programa Giros en tu vida, de la empresa televisiva REPRETEL, en la que se invita al mismo sexólogo para hablar sobre la sexualidad femenina.

Los profesionales del campo de la sexología se han erigido como importantes gurús encargados de dictar pautas con miras a instruir sobre el carácter del buenhacer-sexual. El discurso sexológico ha ido ganando terreno en la arena de las discursividades modernas en torno a la sexualidad, al punto en que "se ha ido creando, progresivamente, una corriente de comunicación entre la problemática sexológica y las aspiraciones sexuales de las personas"

2 El uso de la partícula bio que se agrega en este caso (así como en las categorías biomasculinidad biofeminidad) trata de demostrar el carácter performativo tanto del género como del sexo. Partiendo de la propuesta teórica de Beatriz Preciado (2008), se busca, además, la pretendida naturalidad y el carácter supuestamente estable del dato biológico, mostrando la influencia que ejerce la cultura en su determinación última. 
(Béjin, 1992, p. 285). Siendo que es un hecho casi incuestionable que en la actualidad los medios de comunicación masiva ejercen una influencia importante en nuestra realidad cotidiana hemos querido dirigir esta incógnita hacia un formato de programas televisivos; cuyo principal tema son las relaciones sexuales. Interesa advertir, en este plano, qué tipo de reglas o pautas están implicadas en dicho discurso y los efectos de subjetivación que induce.

Este artículo desarrolla un análisis del discurso sexológico en relación con la sexualidad de las mujeres. Un aspecto esencial de este análisis es la determinación de las temáticas y preguntas a las que se da curso bajo la etiqueta de sexualidad femenina, pues una de las principales tesis por esgrimir en este sentido es que el marco regulatorio en el que se inscribe la sexualidad del sujeto codificado como mujer constituye un corolario de la apuesta biopolítica que hace la ciencia sexual masculina. La representación de biomujer que se maneja en estos programas suele aparecer como una mención exógena, como una nota al pie, que referencia algún aspecto de la sexualidad masculina. En este sentido, no existen intervenciones en las que se explique a los y las televidentes algo similar al rendimiento sexual femenino o sus competencias orgánicas, aspecto que devela la dicotomía erótica que transversaliza las apuestas programáticas que se verán a lo largo del presente texto.

Leer los planos discursivos con los que se escribe el guión de la sexualidad en la actualidad exige emplear instrumentos conceptuales que permitan ir más allá de la lectura, en muchos casos simplista e insuficiente, que se suele hacer de esta temática. Michel Foucault (2005c) sugería a sus lectores la forma en que querría ser leído y señalaba, en este sentido, que sus textos deberían ser vistos como cajas de herramientas con las cuales armar nuevas lecturas, nuevos análisis y acercamientos a diferentes problemas. Es con este horizonte que proponemos rehabitar las propuestas teóricas de distintos autores, a la luz del juego de discursividades que confluyen entorno a la sexualidad. Dado que esta temática ha sido abordada desde muy distintos ángulos en el ámbito académico, se ha optado por incluir aportes de diversos campos, como lo son determinadas disciplinas de las Ciencias Sociales, la Filosofía y la Teoría Queer, sin hacer un especial decantamiento por ninguno de ellos, con el objetivo precisamente de obtener una visión lo más amplia posible de tal fenómeno.

\section{Discurso y arqueología}

En el presente texto partimos de la concepción foucaultiana del discurso, que consiste en una realidad supraindividual, en un tipo de práctica que pertenece a colectivos más que a individuos y que está siempre situado en diversas áreas o campos sociales. Los discursos tienen, no obstante, un fuerte impacto en los individuos, en tanto son quienes los construyen y quienes, de forma reflexiva, se constituyen a sí mismos discursivamente (Diaz, et al., 2005). 
Este planteamiento no puede ser comprendido sin tomar en consideración el campo de la arqueología, que foucaultianamente hablando constituye su marco referencial. El acercamiento arqueológico supone "un análisis comparado que no está destinado a reducir la diversidad de los discursos, sino que está destinado a repartir su diversidad en figuras diferentes. La comparación arqueológica no tiene un efecto unificador, sino multiplicador" (Foucault, 2005b, p. 268). Dicho efecto de diseminación está orientado al examen de las "formaciones discursivas", que consisten en un tipo de regularidad entre los objetos, los tipos de enunciación, los conceptos y las elecciones temáticas que son descritas en un "sistema de dispersión" constituido por un cierto número de enunciados. Por su parte, los enunciados están sujetos a unas "reglas de formación" que determinan sus "condiciones de existencia (pero también de coexistencia, de conservación, de modificación y de desaparición) en una repartición discursiva determinada" (Foucault, 2005b, p. 63).

De tal manera, se busca visualizar las series de formaciones discursivas del saber sexológico que regularizan conjuntos determinados de objetos y enunciados, en función de un cierto número de reglas que sustentan sus condiciones de posibilidad y conllevan una impronta en los cuerpos y los placeres. Dicha marca es descrita por Judith Butler como un efecto de performatividad que "no es un acto único, sino una repetición y un ritual que logra su efecto mediante su naturalización en el contexto del cuerpo" (Butler, 1990, p. 15). En este sentido, habría que analizar la existencia enunciativa, así como el carácter performativo del objeto sexualidad dentro del discurso sexológico, para poder dar cuenta de la conformación de esa realidad a la que denominamos experiencia sexual.

\section{Saber, biopoder y verdad}

Cada uno de los factores de este conjunto ternario constituye un aspecto esencial para identificar y comprender las reglas de formación que siguen los enunciados sexológicos en su puesta discursiva. El posicionamiento de cada uno dentro de la triada no es aleatorio, pues se ha ubicado el poder (en su dimensión bio) entre saber y verdad, con el fin de remarcar el importante rol de articulador que ocupa en dicho arreglo. A continuación veremos algunas de las características principales de cada uno de estos conceptos teóricos.

Como se indicó anteriormente, el elemento esencial para dimensionar el control biopolítico que ejerce la razón sexológica es, sin lugar a dudas, el poder. La importancia de la sexualidad consiste en la forma en que respalda el régimen moderno de biopoder, que Foucault define contrastándolo con el antiguo régimen de poder sobre la vida y la muerte, como una completa tecnología política de la vida (Halperin, 1997). El biopoder se refiere, por lo tanto, al procedimiento político moderno de regular la vida por medio de técnicas experimentadas que hacen posible una alianza estratégica entre el saber especializado (implantado 
como verdad) y el poder institucionalizado en el control de la vida, en general, y de la sexualidad, en particular.

De acuerdo con Beatriz Preciado (2008), la aparición de un régimen posindustrial, global y mediático, a través de los desarrollos acontecidos a lo largo de las últimas décadas, conlleva la constitución de una forma específica de biopoder, en la que confluyen las esferas farmacológica y pornográfica. Los procesos del gobierno de la subjetividad sexual en sus formas moleculares (fármaco) y semiotécnicos (porno) conforman un novedoso concepto que la autora denomina "farmacopornopoder" y que acogemos en el presente artículo.

El saber, por otro lado, juega de acuerdo con Deleuze (2005) un papel de gran importancia por dos razones básicas. La primera consiste en que al problematizar una formación discursiva siempre existirá una relación específica entre saber y ciencia. La segunda razón es que los enunciados solo devienen legibles o decibles en relación con las condiciones que los convierten en tales y que constituyen su inscripción sobre el "zócalo enunciativo" que configura los basamentos del saber. La verdad, por su parte, está según Foucault ligada circularmente a los sistemas de poder que la producen y la sostienen, y a los efectos de poder que la inducen y la prorrogan. La verdad constituye un "conjunto de procedimientos regulados por la producción, la ley, la repartición, la puesta en circulación y el funcionamiento de los enunciados" (2005, p. 156).

Saber, biopoder y verdad constituyen componentes esenciales para asir un tipo de formación heteróclita (propia de la era farmacopornográfica), en la que indubitablemente está implicado el discurso, pero cuya complejidad no se restringe a este y que en el presente texto hemos denominado dispositivo sexológico.

Si bien es cierto, en la actualidad la sexología constituye una profesión ejercida por profesionales, en este artículo se pretende abordar no solamente la expertise inherente a su estatus de disciplina profesional, sino que se busca analizar dicho saber y los efectos de verdad a que induce, mediante una dimensión mucho más amplia, de la que la sexología es tanto producto como productora, a saber, la noción de dispositivo.

Este constructo supone "un conjunto resueltamente heterogéneo, que conlleva discursos, instituciones, arreglos arquitectónicos, decisiones reglamentarias, leyes, medidas administrativas, enunciados científicos, proposiciones filosóficas, morales, filantrópicas, en breve, de lo dicho, así como de lo no dicho" (Foucault, 2001a, p. 299). Argüimos así que el dispositivo sexológico pone en contacto, a través del biopoder, los cuerpos y deseos de un sujeto sexual en modelamiento, con formas específicas de saber tecnificado. El resultado de esta adherencia constituye, por lo tanto, el principal valor analítico de este aparato sexual.

El presente artículo se encuadra dentro de lo que se conoce como el género de estudios discursivos, en tanto se retoman elementos del análisis crítico 
del discurso, así como del análisis foucaultiano del discurso. El material de análisis lo conforman los textos comunicativos de programas televisivos dedicados a temáticas sexuales.

Es importante recalcar que el tipo de discurso que se pretende analizar se inscribe dentro de la corriente cultural de los mass media. Norman Fairclough (1995) señala que una propiedad crucial de algunos de los productos acogidos por estos medios es que intervienen entre lo que se concibe como esferas pública y privada. Este aspecto es de gran importancia puesto que la sexualidad y las construcciones que se desarrollan a su alrededor, no escapan a la influencia que ejercen los medios de comunicación. Se opera, en este sentido, una doble validación, tanto del saber experto en torno a la sexualidad, como de los mismos medios en función de las voces a las cuales dan espacio, que tal y como señala Weeks (1998), contribuyen a configurar el discurso moderno de la sexualidad.

El análisis del discurso sexológico debe ser entendido en su contexto. El discurso manifiesta o expresa, y al mismo tiempo modela, las múltiples propiedades relevantes de la situación sociocultural que denominamos su contexto (Van Dijk, 1990). El estudio del discurso como acción puede adoptar una perspectiva más amplia y poner en evidencia las funciones sociales, políticas y culturales del discurso dentro de las instituciones, los grupos o la sociedad y la cultura en general. Determinar la forma como la sexualidad es dispuesta y aprehendida en el discurso sexológico supone un análisis de la multiplicidad de interrelaciones que dicho discurso (así como el ámbito en el cual se desarrolla) pone en juego.

\section{Selección del material de análisis}

Los espacios televisivos seleccionados para el desarrollo del presente artículo lo conforman los programas En el punto: de la ciencia al sexo, del Sistema de Radio y Televisión de Costa Rica (SINART) y Giros en tu vida, de la empresa REPRETEL S.A. La producción informativa en el ámbito de la sexualidad, de acuerdo con el abordaje específico que interesa en esta investigación, ha experimentado, en los últimos años, un importante aumento, razón por la que se descartaron otro tipo de programas y formatos comunicativos ${ }^{3}$. En este sentido, el primer criterio de discriminación consistió en seleccionar programas televisivos en los que se realizara un abordaje sexológico profesional.

3 El ámbito del entretenimiento mediático muestra una mirada de la sexualidad sumamente estereotipada y sexista, tema que ha sido estudiado en la actualidad por las Ciencias Sociales a través de estudios sobre el impacto de los medios de comunicación y la publicidad. Para ello remítase a: Tamayo, Richard; Gutiérrez, Eduardo. y Herrera, Eliana. (2002). "Rasgos generales del discurso de la radio juvenil sobre la sexualidad y la afectividad"; Pérez, Víctor. y Puigdemont, Dolors. (2005). "Sexualidad y publicidad" y Rico-Villademoras, Fernando. (2005). "Sexualiadad y medios de comunicación”. Si bien es cierto que el análisis de estos fenómenos representa un campo de estudio de gran relevancia, los mismos se alejan de los objetivos planteados en el presente trabajo. 
Se seleccionaron tres emisiones televisivas, de un total de 12, en el caso del programa En el punto: de la ciencia al sexo difundidas durante el año 2009. Los registros de dicho programa se realizaron en las siguientes fechas: (1) 27 de julio del 2009, (2) 15 de junio del 2009, (3) 22 de junio del 2009. Se incluyó además una entrevista al director del programa, el sexólogo Mauro Fernández, llevada a cabo en el programa matutino Giros en tu vida del día 6 de abril del 2009. La selección específica de los programas se basó en aspectos de contenido, de modo que fueron escogidos aquellos que presentasen una mayor variedad temática y que fuesen, por lo tanto, los más representativos posibles respecto a la totalidad de emisiones registradas en relación con el tema de la sexualidad femenina.

La determinación en torno a qué tipo de información sustraer específicamente de cada programa se dio en función de la identificación de aquellas formaciones discursivas que permitieran discernir la configuración de la sexualidad como un objeto de control biopolítico, lo que implicó a su vez determinar la interrelación expresa en el discurso sexológico de los ejes de saber, biopoder y verdad, así como los efectos de subjetivación derivados de dicha conjunción. De esta forma, se tomaron en cuenta las explicaciones, ejemplos, instrucciones, descripciones, prescripciones y recomendaciones que se decantasen en este sentido y más importante aún, la selección de temáticas y preguntas que se valoran en el programa como pertinentes para el análisis de la sexualidad de las biomujeres.

Por su parte, se generó un conjunto de categorías ex post facto, en función de la sistematización del material de análisis. Se identificaron de esta forma ejes de control biopolítico que se decantasen por una aprehensión de la sexualidad bajo un esquema binarizado. En el cuadro que aparece a continuación se muestra dicha configuración:

\begin{tabular}{|l|l|}
\hline \multicolumn{2}{|c|}{ TABLA 1: CATEGORíAS DE ANÁLISIS } \\
\hline Eje de control biopolítico & \multicolumn{1}{c|}{ Binario sexológico } \\
\hline Identidades sexuales & Heterosexualidad / Diversidad sexual \\
\hline Sexo-género & Biohombre / Biomujer \\
\hline Rendimiento sexual & Funcional / Disfuncional \\
\hline Cuerpo & Saludable / Mórbido \\
\hline Fuente: Elaboración propia. & \\
\hline
\end{tabular}

Algunas de estas categorías están presentes solamente en uno de los dos programas, mientras que otras aparecen en todos. Este es un aspecto particularmente relevante, pues el análisis de las ausencias en el discurso es tan importante como el de los aspectos que devienen presencias, en tanto 
la omisión enunciativa de determinados ejes se convierte en un deíctico del ejercicio biopolítico de dominación.

\section{Procedimientos analíticos}

A nivel de procedimientos de análisis, se toma como referente el análisis crítico del discurso (ACD) y el análisis foucaultiano del discurso (AFD). La propuesta metodológica, que se desprende de cada enfoque, aporta distintos insumos que, en su conjunto, permiten llevar a cabo una comprensión más amplia de la temática en cuestión.

El ACD ha sido ampliamente utilizado en el análisis del abordaje informativo de los medios de comunicación masiva. Existen múltiples versiones del ACD, las cuales varían en función de su objeto de estudio y de los procedimientos que privilegie, pero esencialmente de acuerdo con el concepto de discurso que se maneje. El modelo de ACD desarrollado por Jürgen Link (citado por Jäger, 2007, p. 34), define el discurso como un concepto del habla institucionalmente consolidado, que de esta manera determina y consolida la acción, y, concomitantemente, el ejercicio del poder.

En el caso del AFD, como señalan Arribas y Walkerdine (2008, p. 99), cuando Foucault habla del discurso, no está haciendo referencia a una instancia particular del uso del lenguaje -un fragmento de texto, una declaración o rendimiento lingüístico determinado- sino que describe las reglas, divisiones y sistemas de un cuerpo particular de conocimientos. En este sentido, se puede ver cómo ambas definiciones muestran aristas algo distintas, siendo que en la primera se presenta un notable énfasis en la materialidad del discurso y en la segunda se da un mayor acento en el corpus de procedimientos que lo sustentan, y ambos aspectos resultan relevantes para el presente análisis.

De acuerdo con Foucault (1996), una condición para que los sujetos entren en el orden del discurso, es que estos cumplan un conjunto de reglas que hagan el acceso al discurso restrictivo. Esto supone en última instancia un cierto enrarecimiento de los sujetos que hablan. De esta forma, se realiza un análisis de la relación saber, biopoder y verdad, a partir de la posición enunciativa que asumen el presentador en cada programa. En este sentido, el principal núcleo del estudio lo constituye el análisis de la función del experto (Fariclough, 1995), en tanto elemento diferenciador o enrarecedor respecto del resto de sujetos convocados por la escena comunicativa. Se busca dilucidar de esta forma qué tipo de relación establece el presentador con los telespectadores (por ejemplo: alumno-maestro, confidente-confesor, invidente-lazarillo, entre otros).

Foucault señalaba que "si una proposición, una frase, un conjunto de signos pueden ser llamados 'enunciados', no es en la medida en que ha habido, un día, alguien que los profiriera, o que dejara en alguna parte su rastro provisorio; es en la medida en que puede ser asignada una posición del sujeto" 
(2000, p. 159). En concomitancia con este planteamiento y en función del análisis de la relación experto-público televidente, se busca dilucidar los efectos de subjetivación que conlleva este ordenamiento. Siendo que de acuerdo con los presupuestos del AFD este plegamiento subjetivo supone una determinada ética de la formación de sí (Arribas y Walkerdine, 2008), el análisis se enfoca en vislumbrar los posibles efectos de transformación de sí que conlleva la disposición enunciativa configurada por el dispositivo sexológico.

\section{Perfilando una arquitectura corporal femenina}

"Le corps, dans sa matérialité, dans sa chair, serait comme le produit de
ses propres fantasmes [El cuerpo en su materialidad, en su carne,
sería como el producto de sus propios fantasmas]" (Foucault, 2009, p. 17).

El cuerpo femenino contrario al masculino, desde el enfoque sexológico que presentan los programas antes referidos, no obedece a una axiomática del desempeño sexual (Fernández, 2012, p. 144); los ejes fundamentales a los que responde su anatomía, son la pedagogía sanitaria y la prevención anticonceptiva. Véase a este efecto las siguientes intervenciones:

Copresentadora: Pasando a la mujer Mauro, hemos recibido muchos correos sobre el DIU ${ }^{4}$ y una pregunta constante es, si el DIU produce infecciones en la mujer, o si la puede dejar estéril (Fernández, 27 de julio del 2009).

Copresentadora: Mauro brincamos nuevamente a la sexualidad de la mujer, en este caso sobre los hongos vaginales (Fernández, 15 de junio del 2009).

La adecuación temática que realiza la copresentadora del programa materializa un giro discursivo que denota una designación biopolítica taxativa de los códigos semiotécnicos de la masculinidad y la feminidad. Este enlistamiento binario, introducido por las fórmulas "pasando a la mujer" y "brincamos nuevamente a la sexualidad de la mujer", hace coincidir lo femenino con una economía libidinal deserotizada, en donde dispositivos intrauterinos, infecciones, esterilidad y hasta agentes micóticos se convierten en componentes primordiales de la pedagogía sexual de la biomujer. Para poder comprender esta traslación, debemos partir de que "el cuerpo es un texto socialmente construido, un archivo orgánico de la historia de la humanidad, como historia de la producción-reproducción sexual, en la que ciertos códigos se naturalizan, otros quedan elípticos y otros son sistemáticamente eliminados o tachados" (Preciado, 2002, p. 23). El siguiente extracto muestra de manera más clara las implicaciones de este viraje:

Copresentadora: Mauro si hay padres que, eh, que tienen hijos adolescentes, y uno de estos hijos, si es una chiquilla se nos embaraza, si es un varón están estas cosas de pornografía, y este mundo que referís, si se mete en todas esas cosas que literalmente atentan contra su vida como jóvenes, ¿significa que fallaron los padres? (Fernández, 27 de julio del 2009).

$4 \quad$ Dispositivo intrauterino. 
Podemos ver cómo se empieza a perfilar una circunscripción sexo-genérico que estandariza lo que es "entrar en materia femenina", en donde los fenómenos del embarazo adolescente y la pornografía (descritos con inmenso estupor, puesto que para los jóvenes, estos "literalmente atentan contra su vida”), adquieren un carácter de exclusividad. Aquí la cuestión es, precisamente, que los hechos nunca "hablan por sí mismos", sino que una red de dispositivos los hace hablar (Žižek, 1994). El dispositivo sexológico, en consonancia con los mecanismos de poder farmacopornográfico, conjugan un efecto de agenda setting (Rodríguez, 2004), que determina las inquietudes intrapersonales de cada individuo, de acuerdo con una codificación a nivel de género y sexo. Se descarta de plano que las biomujeres adolescentes consuman pornografía, o que los biohombres de este mismo grupo etario tengan alguna implicación con el embarazo. El efecto último que conlleva esta segmentación es, por lo tanto, una naturalización de cánones impuestos socioculturalmente.

\section{El sexo mórbido}

En diversos episodios de En el punto: de la ciencia al sexo se hace énfasis sobre la gran demanda que genera el programa, resaltando el hecho de que se recibe cotidianamente una inmensa cantidad de preguntas por parte de los telespectadores. La escogencia de preguntas, más que un acto incidental, constituye un aspecto de gran relevancia en lo que respecta a la configuración del discurso del programa. La figura de gatekeeper resulta muy valiosa para la comprensión de este proceso. Este término sirve para identificar "a las personas que, individual o colectivamente, en los medios de comunicación son los encargados de seleccionar las noticias que aparecerán en su medio" (Rodríguez, 2004, p. 4). El proceso de selección de preguntas es homólogo al de noticias, pues en ambos casos se genera un tamiz que privilegia determinados contenidos y descarta otros.

En el programa se abordan una serie de trastornos médicos, especialmente, padecimientos ginecológicos que constituyen la materia esencial de lo que denominaremos una pedagogía sanitaria. Dado que en buena parte del discurso sexológico lo sexual pasa ineluctablemente por la escenificación de lo genital es importante determinar qué atribuciones recibe la genitalidad femenina. El siguiente extracto constituye la respuesta a una pregunta realizada por una televidente, sobre cuáles son las enfermedades a las que se expone una persona que ha tenido pocas parejas sexuales en su vida:

Sexólogo: Cuando hemos estado con un compañero sexual que ha tenido más de una pareja, es decir que ya tiene su pasado sexual, cualquier enfermedad venérea puede estar, puede estar el herpes, puede estar la clamidia, puede estar el papiloma, puede estar el mismo SIDA, puede estar la hepatitis b, puede estar el chancro, el cancroide, pueden originarse (Fernández, 15 de junio del 2009). 
Lo que interesa resaltar de esta resolución brindada por el sexólogo, no es la veracidad o falsedad de la información proporcionada. Es indudable que las enfermedades de transmisión sexual existen y dada la veracidad de este hecho, se vuelve igualmente irrefutable afirmar que el abordaje que se haga de estas resulta definitorio para la identificación del sujeto portador. En este sentido, es importante reparar el tipo de interrogantes o inquietudes que son acogidas y cuál es el tratamiento que reciben. Así, el sexólogo coloca al biohombre como un transmisor activo por excelencia de enfermedades venéreas, mientras que la biomujer aparece como un receptor pasivo. El aspecto de mayor importancia en este caso es el hecho de que la respuesta del sexólogo devela una inquietud por el contagio que hace aparecer la sexualidad como un mundo lleno de peligros. El cúmulo de amenazas venéreas desglosado constituye un llamado dirigido directamente a las biomujeres con el acometido de llevar a cabo "prácticas sexuales seguras".

A pesar de ser un llamado loable, esta égida anti-infecciosa no ejerce su efecto de forma homogénea, pues en las intervenciones en torno a la sexualidad del biohombre (mayoritarias por demás), este tipo de consideraciones están ausentes. De modo que, estamos frente a un discurso sexológico que fomenta una regulación profiláctica de la sexualidad, que atañe de forma preponderante a las biomujeres. Esta tendencia pareciera un resabio de prácticas que otrora ubicaran a las biomujeres como un "objeto peligro". Verbigracia de ello, durante la Segunda Guerra Mundial, el Departamento de Guerra de los Estados Unidos de Norteamérica comenzó a elaborar propaganda con el fin de prevenir el contagio de enfermedades venéreas a sus soldados y de esta forma reducir el número de bajas en los campos de batalla (National Library of Medicine, 2003). La sexualidad pasó a ser un asunto de salubridad decisivo para la Seguridad Nacional (e incluso mundial), en donde las mujeres se convierten en el principal foco de atención infecciosa. Las mujeres pasaron a formar parte de lo que Michel Foucault denomina -dentro de la lógica de los siglos XVII y XVIII- una "enfermedad reinante", que constituye:

Una especie de enfermedad consustancial, por decirlo de algún modo, que se confunde con un país, una ciudad, un clima, un grupo de gente, una región, una manera de vivir. En esa relación masiva y global entre un mal y un lugar, un mal y una determinada gente, se definía y caracterizaba la enfermedad reinante" (2004, p. 80).

El principal objetivo de esta propaganda militar consistía en convencer a los soldados del peligro que significa mantener relaciones sexuales con cualquier tipo de mujer (representadas mediante la imagen iconográfica de la prostituta: sujeto deleznable por antonomasia para la moral conservadora) y de esta forma reducir la incidencia de enfermedades venéreas. Si bien es cierto que esta tendencia no era novedosa, pues ya la ciencia sexual decimonónica "se defendía como una instancia soberana de los imperativos de higiene, uniendo los viejos temores al mal venéreo con los temas nuevos de 
la asepsia" (Foucault, 2005a, p. 68), su novedad residió en llevar a cabo una instrumentalización biopolítica del miedo, mediante una campaña mediática de carácter masivo.

Dicho discurso sexológico reproduce esta lógica invirtiendo su implementación, en tanto que son las mujeres las que deben, en primera instancia, disuadirse a sí mismas de la peligrosidad del contagio y procurar por consiguiente auto-preservarse de tal amenaza. Ciertamente, no se puede afirmar que para el discurso sexológico la enfermedad reinante es intrínseca a la corporalidad de las mujeres, no obstante, sus efectos dentro del patrón modélico heteronormativo sí lo son. Es justamente en esta medida que los genitales femeninos (como epicentro sexológico de la sexualidad de las mujeres) se convierten en un área ginecopática, en un terreno mórbido que es tanto un espacio de vulnerabilidad, como un foco de contaminación. Las siguientes intervenciones refuerzan de forma palmaria el carácter deserotizado que adquiere la sexualidad femenina:

Copresentadora: Eh, aquí nos preguntan si una mujer virgen puede usar tampones (Fernández, 27 de julio del 2009).

Copresentadora: En una mujer joven Mauro, digamos entre los 20 y los 30 años, ¿es preocupante que haya una pelotita en el pecho? (Fernández,15 de junio del 2009).

Copresentadora: En el caso del virus del papiloma Mauro, ¿siempre vamos a tener un cáncer? (Fernández, 22 de junio del 2009).

La presencia de estos contenidos nos muestra una escenificación unifacética de la biofeminidad, cuyo carácter bio se basa en aspectos meramente ginecológicos, que soslayan completamente la dimensión del placer. Si en el caso del biohombre el ciclo de frustración-excitación suele aparecer como el medio de control biopolítico por excelencia, en el caso de la biomujer, este control pareciera encontrarse en un estado embrionario, ejercido por medio del aparato médico de regulación, a través del ciclo disciplina-seguridad, como solía suceder a lo largo del siglo XIX. La constante del trastorno, además de vivificar un universo sexual anti-lascivo, conlleva una delimitación de las coordenadas bioestéticas y reproductivas del cuerpo femenino.

Sexólogo: Un atraso menstrual, lo hemos repetido en este programa, produce acné, produce sobrepeso, ve que la ve gordita, produce que se llene de vellos, la puede hasta dejar estéril un problema menstrual, le puede provocar una diabetes, a largo plazo le puede provocar una osteoporosis, le puede provocar un cáncer, todo lo que hemos mencionado, de todo el ciclo de lo que es un Stein Leventhal, a lo largo de todas las décadas de la vida de una mujer (Fernández, 27 de julio del 2009).

En este caso la peligrosidad de un atraso menstrual comporta distintos frentes. Por un lado, es la fuente potencial de diversos padecimientos médicos, como la diabetes, la osteoporosis y hasta el cáncer. Por otro, conlleva el riesgo de la esterilidad, que no atañe solo a los designios procreativos de una biomujer en particular, sino que constituye una problemática de índole heterosocial, en tanto la obligación de reproducción de la especie que incumbe a las 
mujeres, es el sistema de explotación sobre el cual se funda económicamente la heterosexualidad (Wittig, 2007). Finalmente, el tercer foco de amenaza que representa un atraso menstrual es la descomposición de los preceptos hegemónicos de lo que se entiende por belleza femenina.

Dentro del sistema de pedagogía sanitaria instalado en el discurso sexológico del programa, la gordura y el hirsutismo aparecen como antivalores que contradicen los códices estéticos que deben estar presentes en el cuerpo de cualquier biomujer. En este sentido, el cuerpo como superficie de placer, cede terreno frente al fantasma de la morbilidad, que no se circunscribe meramente a la realidad empírica de una u otra enfermedad, sino que conlleva una red de mecanismos biopolíticos que trascienden dicha facticidad.

\section{El panóptico contraconceptivo}

La mirada médica que se tiende en los programas sobre la sexualidad de la biomujer, se articula mediante un conjunto de mecanismos de regulación propios de lo que Beatriz Preciado (2008) denomina la era farmacopornográfica. La autora arguye que si la era dominada por la economía del automóvil se denominó fordismo, se llamará farmacopornismo a esta nueva economía dominada por la industria de la píldora, por la lógica masturbatoria y por la cadena de excitación-frustración en la que se apoya. Preciado enfatiza que en esta forma de capitalismo, el deseo sexual y la enfermedad comparten una misma plataforma de producción y cultivo, a saber, que no existen sin los soportes técnicos, farmacéuticos y mediáticos capaces de materializarlos. Diremos, por nuestra parte, que la patología como gendarme de la actividad sexual encuentra un correlato importante en el auspicio que el saber sexológico otorga al control del cuerpo femenino, mediante la prescripción de una serie de compuestos medicamentosos que materializan precisamente esa interfaz entre el farmacopoder y el pornopoder.

En esta línea, las píldoras anticonceptivas constituyen -de acuerdo con la disposición temática programada- una de las principales fuentes de regulación biopolítica de la sexualidad femenina. Beatriz Preciado retomando el Método Iconográfico Aby Warburg, vincula mediante un efecto de trazabilidad visual la figura del panóptico de Jeremy Bentham, con la forma que tienen los paquetes de pastillas anticonceptivas que se distribuyen en la actualidad. Para Preciado, los motivos arquitecturales de Bentham son de cierta forma transmutados, de modo que la píldora anticonceptiva toma la forma de un "panóptico comestible" que presenta las siguientes características:

Dispositivo ligero, portable, individualizado y afable, permite modificar el comportamiento, temporalizar la acción, regular la actividad sexual, controlar el crecimiento de la población y modelar la apariencia sexual (refeminizándola sintéticamente) de los cuerpos que se la auto-administran. La torre de control fue remplazada por los ojos de la consumidora dócil que, sin tener necesidad de una mirada exterior, regula 
su propia ingestión siguiendo el calendario de una plaqueta circular o rectangular. El látigo es remplazado por un sistema práctico de administración oral. La celda es en adelante el cuerpo mismo de la consumidora, que se ve bioquímicamente modificado sin que, una vez ingerido el compuesto hormonal, uno pueda determinar sus efectos exactos, ni su procedencia (Preciado, 2008, p. 161).

La anticoncepción farmacológica otrora descrita como la base para la liberación sexual femenina, constituye una -sino la más- sofisticada herramienta de sujeción de la historia. El panóptico ejerce una mirada abarcadora, pero su mirada no es esa mirada amparada en las anteriores reglamentaciones de corte disciplinario; en nuestros días, estos visores funcionan mostrando un simple atisbo de visión, casi a la manera de una ojeada furtiva, que resulta ser, no obstante, no menos acaparadora, no menos total, no menos represiva. Por el contrario, esta mirada de apariencia engañosa, es aún más efectiva que en tiempos pasados, pues la misma logra interiorizarse de forma mucho más certera e inequívoca en los cuerpos, dictando de esta forma una manera de encuadrar el deseo y el placer. En el siguiente extracto se muestra el carácter que asume la receta del medicamento anticonceptivo como mecanismo de biocontrol sexológico:

Sexólogo: En general, queremos por muchas razones que la mujer que está empezando su primer paquete, por primera vez, hoy dice, el doctor me indicó Diane, me indicó Yasmín, me indicó Yas, hoy voy empezarlo, que se espere, que se cubra durante el primer mes con el preservativo, no tanto porque las pastillas no funcionen, sino que con frecuencia durante ese primer mes, es donde más vemos los olvidos, es decir, todavía no ha hecho un hábito las pastillas anticonceptivas, y entonces esa mujer comienza a tomarla, y se le olvida en esas primeras semanas, los estudios indican que ya a partir del segundo mes, no sólo la pastilla la va a proteger, sino que con frecuencia buena parte de nuestras mujeres, ya tiene una toma más consciente durante ese segundo paquete (Fernández, 15 de junio del 2009).

La instalación del dispositivo panóptico no es inmediata, conlleva un proceso de modulación paulatina y continuada hasta que este alcance a posicionarse como un verdadero centro de autoregulación subjetiva. "Hacer hábito" o "tener una toma consciente" significa incorporar un contingente farmacológico de gestión biológica que supone tanto un control de la vida cotidiana, como una predeterminada dosificación bioquímica del cuerpo. Los olvidos constituyen una pieza clave para el engranaje de la maquinaria farmacológica, pues:

La lógica heterosexista que domina la píldora, responde a esta doble exigencia contradictoria: toda mujer debe ser a la vez fértil y capaz de reducir la posibilidad de fertilidad de manera asintóticamente próxima a cero, sin por lo tanto anularla completamente, de manera que la concepción accidental permanezca como posible (Preciado, 2008, p. 164).

Cada omisión o descuido hacen inteligible la existencia de este cero probabilístico no consumado. El sistema no puede ejercer un control total, debe generar intersticios, zonas de fuga, espacios para el error. El olvido refuerza la lógica del sistema en la medida en que hace de la reproductibilidad una realidad factible. 
Sexólogo: La pastilla en realidad lo que hace es una seguidilla, es decir, es como una especie de escalera, son 21 peldaños para lograr la anticoncepción (Fernández, 15 de junio del 2009).

Siguiendo a Foucault, el mayor efecto del panóptico consiste en "inducir en el detenido un estado consciente y permanente de visibilidad que garantiza el funcionamiento automático del poder" (2005, p. 204). La consecución de la "seguidilla" de 21 peldaños que supone el consumo continuo de la píldora conlleva un estado de vigilancia constante que la biomujer debe ejercer sobre sí misma. Quizá uno de los mayores éxitos de los fármacos anticonceptivos consiste precisamente en el desarrollo de una mecánica de consumo por default, es decir, la instalación de un proceso de ingesta automatizada en la que el sujeto femenino se convierte en un individuo recluido en su propia corporalidad.

\section{Representaciones de la "mujer" en código binario}

Tanto en la sección del programa Giros en tu vida en la que se entrevista al sexólogo Mauro Fernández, como en el programa En el punto: de la ciencia al sexo, se presenta un juego subrepticio de imágenes contrapuestas que giran en torno a determinadas representaciones de lo femenino. Estas imágenes producen un efecto de localización que conllevan la configuración de una fisonomía corporal y moral de ese sujeto al que se identificada como mujer. Véase a continuación la forma en que operan algunas de estas representaciones:

\section{"La doña"}

En dichos programas se muestran dos figuras antagónicas entre sí, la primera aparece identificada por el sintagma de "la doña", mientras que la segunda es un sujeto tácito que constituye el anverso de la imagen inicial.

Sexólogo: El costarricense le tiene mucha confianza a la doña, en esto hay que ser claros, en lo que no se le tiene confianza, es en el tema sexual (Figueroa, 6 de abril del 2009).

En esta intervención se pueden apreciar algunas características que develan quién es este personaje. "La doña" es primeramente alguien que tiene una gran proximidad con el biohombre (=el costarricense), excepto en lo que tiene que ver con la sexualidad. Avanzaremos desde ya que esta designación identitaria es una variable dependiente de la función sexual masculina.

Sexólogo: Cuando se tiene una relación por fuera, y digamos que un varón dice, porque eso sucede, uy estoy fallando, será que la doña ya no me gusta, será que mi mujer, en realidad será, voy a irme a buscar algo afuera, eso sucede, y se da cuenta de que, no va a funcionar, por qué, porque a lo mejor el nivel de estrés, que significa ir a conquistar una muchacha, estar en una situación así, prácticamente, se requiere más integridad de la erección para funcionar (Figueroa, 6 de abril del 2009). 
En el relato que nos presenta esta intervención aparecen tres actores: un "varón", una "doña" y una "muchacha". La narración se centra en las peripecias del funcionamiento sexual del "varón", cuya localización respecto al adentro y al afuera de la monogamia matrimonial determina la identidad del resto de personajes en escena. Cuando el "varón" se localiza dentro de este vínculo, el individuo con el que se relaciona recibe el nombre de "la doña" (="su" mujer) y cuando se encuentra fuera del mismo, es denominado "muchacha" (=mujer "ajena").

La relación de pertenencia que establezca el "varón" respecto a la biomujer con la que pruebe (tanto en el sentido de demostrar como de corroborar) su integridad eréctil, es determinante para la localización del sujeto femenino. El apelativo "doña" además de tener una fuerte carga misógena en la sociedad costarricense simboliza cualquier cosa menos un sujeto erotizable y, en este sentido, la enunciación de dicha fórmula, constituye una vía de reforzamiento de las relaciones de sujeción de género que prevalecen en la sociedad actual.

\section{"La mujer-que-cela"}

Los celos constituyen la materia prima mediante la cual se formula otro tipo de localización de la biomujer identificada, en este caso, como "la mujer-quecela"5. Es muy posible que este sujeto sea el mismo que "la doña", dadas las importantes similitudes que existen entre ambos. No obstante, cada construcción conlleva particularidades que merecen ser vistas por separado.

Sexólogo: Esa mujer, que cela a su hombre por todo, en realidad utiliza elementos que no son ciertos, hasta se miente a ella, y miente en torno a toda la vida de su esposo .... hay que tener una, una conversación muy sincera, porque puede que ella invente mucho, para tratar, porque en Costa Rica existe una cosa que es, sacar de mentira o verdad, entonces empieza con una serie de mentiras, a ver dónde sale la verdad, y la verdad es que, lo que le puede resultar, es una pérdida marital, sin justificación (Figueroa, 6 de abril del 2009).

Este sujeto, al igual que "la doña", se hace visible gracias a la interacción que mantiene con el sujeto marital masculino dentro del encuadre narrativo sexológico. Reparemos ahora algunas de las características que le son atribuidas en el extracto anterior:

"Cela a su hombre por todo".

"En realidad utiliza elementos que no son ciertos".

"Se miente a ella y miente en torno a la vida de su esposo".

"Inventa mucho".

Utiliza artilugios de verdad/mentira.

Esta radiografía de "la mujer-que-cela", nos muestra que se trata de un sujeto con múltiples rasgos paranoides, que genera, sin justificación, una atmósfera negativa rayana en lo disfuncional. La consecuencia más importante de esta

$5 \quad$ Con el uso de guiones se pretende visibilizar el carácter ontologizante que asume esta nueva localización. 
disposición obsesa es una potencial "pérdida marital" que toda biomujer por consecuencia debe procurar evitar. En el epílogo de la intervención, el sexólogo intenta acoplar infructuosamente su discurso a una visión género-sensitiva, puesto que una vez presentada la casuística del sujeto celoso -esencialmente femenino- procura nivelar o empatar el arbitrio moral al que llega, mostrando que dicha circunstancia también se da en la acera contraria:

Sexólogo: Muchísimos hombres realmente se cansan, muchísimas mujeres realmente se cansan, de los celos irreales, de los que padece su mujer (Figueroa, 6 de abril del 2009).

La frase "muchísimas mujeres realmente se cansan", aparece como un elemento exógeno a la oración, que evidencia su inverosimilitud cuando es cotejada con la siguiente proposición: "de los celos irreales, de los que padece su mujer". Esta falta de concordancia de género que prefigura una suerte de lapsus gramatical devela la carga misógina que instituye la figura de "la mujerque-cela" como una unidad inteligible.

\section{"La mujer-honesta"}

La tercera localización identificada, es la de "la mujer-honesta", misma que constituye el par dicotómico de la prostituta. El terreno que permite situar a este nuevo sujeto, es la inquietud por el contagio venéreo:

Sexólogo: Hubo un momento en Costa Rica, y yo participé de eso, cuando era uno estudiante de medicina, iba uno con el Ministerio a darle charlas a los chiquillos de sexto grado, quinto grado, y les decía, las enfermedades venéreas se relacionan con las prostitutas, hoy decimos que no, porque eso fue un grave error, por qué, porque todas las mujeres honestas creen que están protegidas, y no es cierto, por qué no es cierto, imaginémonos que este señor es muy bandido, llamémoslo como se llama siempre a ese señor aquí, Pancho, Pancho es muy bandido y anda con todo mundo, va a prostíbulos que esto, que el otro, resulta que Pancho, se enamoró de Pancha, que es una buena mujer, que nunca había estado con ningún hombre anteriormente, es más, Pancho cuando la conoció se hizo fiel, pero ya tenía todas las infecciones que había adquirido en su vida sexual previa, cuando tiene relaciones con Pancha, cuando se casaron, le transmite todas esas infecciones, pero como Pancha sólo ha estado con Pancho, dice, yo no tengo ninguna infección, y ese es el grave error (Figueroa, 6 de abril del 2009).

Según Gilman (1994), durante la década de 1980, una vez que los homosexuales dejan de ser estigmatizados como la única población portadora de $\mathrm{VIH}$, aquellas mujeres que se encontraban fuera del ámbito de la "respetabilidad", pasaron a ser marcadas como fuente de enfermedad. Ciertamente, en el extracto anterior la prostituta deja de ser identificada como la etiología del contagio, no obstante, su estatus de "no-respetabilidad" se mantiene incólume y sigue primando de esta manera una visión moralista en lo que respecta a la venta de servicios sexuales. 
Si antaño la prostitución era un problema de salubridad, en este discurso en cuestión se vuelve un problema de moralidad. Por oposición a la forma en que es representada la prostituta, se identifican prácticas que portan un emblema con una inscripción que reza: "la mujer-honesta". De esta forma, en la descripción que se hace de "Pancha", esta aparece como "una buena mujer, que nunca había estado con ningún hombre anteriormente". La virginidad de este personaje se constituye así en la deixis de su bondad. Se configura lo que Itziar Ziga (2008) denomina un "estatus de feminidad legítima", que en este caso está dado en función de un umbral axiológico que determina cuáles biomujeres pueden ser ungidas con el don de la "honestidad" y cuáles no.

\section{Fábula sexológica de la pareja heterosexual}

El marco relacional del que parte la visión sexológica de los programas analizados, responde a una lógica de pareja heterosexual inscrita en la institucionalidad del matrimonio. Esta lógica, denominada por Monique Wittig (2007) como pensée straight o pensamiento heterosexual, basa su funcionamiento en la creación de un otro diferente en todos los niveles, que se vuelve una necesidad ontológica para todo el conglomerado de ciencias y disciplinas. En el extracto del texto que aparece a continuación, se muestran los efectos de esta división sexual sostenida por el discurso sexológico. El primer fragmento constituye la pregunta de una televidente (efectuada en vivo por vía telefónica), mientras que el segundo bloque corresponde a las intervenciones de los presentadores y el sexólogo:

Televidente: Mi problema es, que yo, no tengo como muchos deseos, de relaciones sexuales, mi esposo sí, por él todos los días, yo por mí una vez al mes, inclusive verdad, entonces no sé, a qué se debe esto.

Presentadora: ¡Qué buena pregunta!

Sexólogo: Ahora, yo primero quisiera felicitar a este programa [Giros en tu vida], este programa es representativo del acontecer sexual costarricense, siempre que me siento aquí, recibo la pregunta clásica, así, de la población, eso habla del tipo de público que se tiene, y menciono esto porque si a los 30 , estoy sin deseo sexual, ¿cómo voy a estar cuarenta años después?

Presentador: Correcto.

Sexólogo: ¿Cómo voy a estar 20 años después? Entonces de alguna manera, la mujer debe cuidar el deseo sexual, si hoy usted llega y dice, mira no tengo ganas de levantarme, mira yo no puedo dormir, mira no puedo comer, usted consulta con un médico, pero de alguna manera se nos está quedando ese grupo de mujeres que dice, yo no quiero tener relaciones, y que no está consultando, a estas edades, y como suele suceder, ya hoy sabemos que en más del 80 por ciento de los casos, es: de tipo físico, es, tiene una enfermedad, ya sea que tiene mala la tiroides, que tiene malo el ovario, que tiene malo una glandulita especial que se llama la hipófisis, que el hígado no está funcionando bien, pero es importante que sepa que no es mental, sobre todo, y esto es muy importante, y hay que decírselo a la mujer, el otro día hablamos, de qué cosas desconoce la mujer, la mujer, a veces no sabe, que decirle no a un hombre, decirle no a su hombre. 
Presentadora: Sí, un rechazo digamos.

Sexólogo: Es un rechazo, que no se, que no se evalúa como me está rechazando sexualmente, sino, me está rechazando a mí, es decir, no es una negativa puntiforme, el hombre lo siente como un, como una anulación completa de su ser, es más, los estudios dicen, que el desencadenante, no el precipitante, sino lo que hace que un, que un hombre opte de manera impulsiva, por un vínculo afuera, suele ser una negativa sexual de su pareja, entonces hay que tenerlo presente, porque el hombre es muy vulnerable, a una negativa (Figueroa, 6 de abril del 2009).

La televidente que consulta, señala que su "problema"6 consiste en no tener deseos de mantener relaciones sexuales con su esposo. Quizá el aspecto más importante que se puede disgregar de las intervenciones ulteriores es la circunscripción de los espacios en los que se configura lo que se entiende por sexualidad femenina. Un aspecto llamativo es que los ámbitos que se identifican en el discurso sexológico actual resultan ser muy parecidos a los que existían a principios del siglo XX en torno a la figura de la histérica, cuya sexualidad y placer:

Se construyen en el espacio de tensión y de encuentro de al menos dos instituciones: la institución matrimonial heterosexual, en la que las mujeres están sujetas a sus maridos y las instituciones médicas, en las que las mujeres están sujetas a la jerarquía clínica como pacientes (Preciado, 2002, p. 91).

Como se puede observar, el cuerpo femenino es sometido a una intensa auscultación clínica, a partir de la cual se determina que los "problemas de deseo" de las mujeres (“más del 80\%” según el sexólogo), responden a una enfermedad de tipo físico: "ya sea que tiene mala la tiroides, que tiene malo el ovario, que tiene malo una glandulita especial que se llama la hipófisis, que el hígado no está funcionando bien". Esta descripción que por momentos pareciera tratarse de la revisión mecánica de un automóvil conlleva ineluctablemente una visión patológica, que responde al adoctrinamiento médico de la sexología.

La institucionalidad del matrimonio apuntada por Preciado tiene un peso no menos importante en la discusión respecto a la negativa de muchas mujeres a tener relaciones sexuales con su cónyuge. En este enfoque sexológico, la sexualidad femenina aparece asociada al "hacer sexual" masculino configurando así una suerte de fábula heterosexual, en la que el biohombre aparece como el operador supremo. Irène Jonas (2009) señala que muchas de las nuevas prescripciones psi para parejas, en apariencia dirigidas a los dos sexos (hombre y mujer, en el estricto sentido heterosexual de ambos términos), lo que hace en realidad es explicar a las mujeres cómo comportarse y cómo corresponder a lo que los hombres esperan de ellas. Repasando los argumentos que

$6 \quad$ Entrecomillamos la palabra problema, porque el hecho de que la persona consultante defina su situación en estos términos, no implica necesariamente que esta sea la mejor manera de concebirla. La información que se brinda resulta insuficiente para determinar si realmente se trata de un problema que atañe a la persona en concreto; de modo que asumirlo como tal, es partir de un a priori, que hace cualquier conclusión espuria de entrada. 
se brindan para explicar las consecuencias del rechazo de una biomujer a un biocopulador masculino es claro que la propuesta anteriormente presentada no dista mucho de esta tendencia. El rechazo, se indica:

- "El hombre lo siente como una anulación completa de su ser".

- Además de que es "lo que hace que un hombre opte de manera impulsiva por un vínculo afuera, suele ser una negativa sexual de su pareja”.

En esta visión sexológica no existe el más mínimo cuestionamiento respecto al por qué de esta anulación del ser, ni de la "opción impulsiva" que supuestamente conlleva. Por el contrario, son naturalizadas y utilizadas como referentes que validan el encauzamiento de la conducta femenina hacia el estándar coital masculino. Estos postulados muestran la existencia de una corriente de continuidad entre la sexología y los discursos clericales, en tanto "los sucesores de la religión, muchas veces defienden el discurso de una sexualidad coito-céntrica y reproductiva, que prescribe el matrimonio o una unión estable, que interpreta el deseo femenino en la perspectiva masculina y que condiciona, persigue o ignora a quien se aparte del modelo dominante" (Soares, 2008, p. 45). De este modo, todo parece indicar que el discurso sexológico está en concomitancia con una ideología extendida que profesa la primacía y la incontrolabilidad del impulso sexual masculino (Rich, 1993), en la que el sujeto femenino se convierte en un monigote penetrable dentro de una fábula heteronormativa sexológica.

\section{Reflexiones finales}

El discurso sexológico se fundamenta en un sistema de regulación biopolítica que produce efectos de subjetivación, en un proceso que de acuerdo con Foucault, implica: prácticas divisorias ${ }^{7}$ (2001b, p. 1042). El discurso sexológico de los programas analizados constituye un deíctico de cómo son movilizadas estas prácticas sobre la superficie privilegiada del cuerpo de las biomujeres, reproduciendo un parcelamiento subjetivo profundamente arraigado en la cultura. La lógica binarizada que subtiende los valores sexuales de la época actual (así como muchos de los vigentes en tiempos anteros), se fundamenta en la "necesidad de trazar y mantener una frontera imaginaria entre el sexo bueno y malo" (Rubin, 1993, p. 14).

Así, la insistencia tácita o explícita en torno a relaciones de pareja monógamas, de carácter privado, no comercial y heterosexual conforman un escenario en el que ciencia, cultura, familia y religión conllevan espirales concéntricas de control biopolítico, que otorgan márgenes muy estrechos para el agenciamiento de la subjetividad, en la medida en que refrendan dicha frontera maniquea.

$7 \quad$ Ejemplos clásicos de prácticas divisorias son las particiones entre el loco y la persona de espíritu sano, el enfermo y el individuo con buena salud, el criminal y el bueno, entre otras. 
Según Baudrillard (2000, p. 113) "con la modernidad entramos en la era de la producción del Otro. No se trata ya de matarlo, devorarlo o seducirlo, ni de enfrentarlo o rivalizar con él, tampoco de amarlo u odiarlo; ahora, primero se trata de producirlo". En esta línea, el discurso sexológico es, por un lado, un ente reproductor de prácticas divisorias que refuerzan determinados binarios y, por otro, un productor de discursos que nutren la lógica del binarismo en sí mismo. Esta disposición supone un espacio exiguo para la alteridad, en la medida en que se establecen coordenadas de objetivación fijas, que en este caso producen un sujeto llamado "mujer", con los ingredientes de una moral tradicional adobada con un exterior de cientificidad.

La sexualidad del biohombre constituye el estandarte sexológico en ambos programas, razón por la que la biomujer (su anverso "natural") ocupa un lugar secundario que la relega a un estatuto de sujeto sexual adjunto. No existen, por lo tanto, prescripciones en torno al rendimiento o la función orgásmica femenina, pues de acuerdo con esta sexo-lógica en cuestión, dichos aspectos no atañen a tales coordenadas sexo-genéricas. Los ejes fundamentales a los que responde la anatomía femenina pasan a ser la pedagogía sanitaria y la prevención anticonceptiva. A partir de esta segmentación taxativa de lo que se supone que constituyen las "temáticas sexuales de las mujeres", el biocuerpo femenino está sujeto a una constante de la "deficiencia"; no obstante, la biomujer no sería un ser deficiente por acción (dado que para el dispositivo sexológico no hay en ella ningún accionar significativo que pueda ser objeto de adiestramiento y corrección), sino que esta es deficiente por definición.

La concentración en las secuelas que producen las enfermedades venéreas (inquietud por el contagio) implica un carácter deserotizado y culpabilizante de la sexualidad femenina, en donde el cuerpo, como superficie de placer, cede terreno frente a la morbilidad. La contraconcepción, por su parte, constituye un medio dispuesto por el discurso sexológico, que agrega una celda más al control biopolítico de sexualidad femenina. La heterosexualidad, en su expresión más tradicional, es naturalizada reiteradamente en el programa, ya sea por la ausencia de contenidos en los que se contemplen otras formas de vinculación sexual, o por la reafirmación de tal "naturaleza". Esta tendencia hace patente la preponderancia del pensamiento heterosexual reflejado en el programa, ya sea a través de distintas localizaciones del sujeto femenino ("la doña", "la mujer-que-cela", "la mujer-honesta"), o a partir de la dinámica sexual descrita como adecuada entre "hombre" y "mujer", en lo que hemos denominado la fábula sexológica de la pareja heterosexual, a saber, un esquema matrimonial de esposa servil y marido servido. 


\section{Referencias bibliográficas}

Arribas-Ayllon, Michael \& Walkerdine, Valerie. (2008). Foucauldian Discourse Analysis. En Carla Willig \& Wendy Stainton-Rogers (eds.), The Sage Handbook of Qualitative Research in Psychology. Londres: SAGE Publications.

Baudrillard, Jean \& Guillaume, Marc. (2000). Figuras de la alteridad. México: Taurus.

Béjin, André. (1992). El poder de los sexólogos y la democracia sexual. En Philippe Ariès \& André Béjin (eds.), Sexualidades Occidentales. Buenos Aires: Editorial Paidós.

Butler, Judith. (1990). El género en disputa. El feminismo y la subversión de la identidad. México: Editorial Paidós.

Deleuze, Gilles. (2005). Foucault. Buenos Aires: Editorial Paidós.

Diaz-Bone, Rainer; Bührmann, Andrea; Gutiérrez, Encarnación; Schneider, Werner; Kendall, Gavin \& Tirado, Francisco. (2007). El Campo de análisis del discurso Foucaultiano. Características, desarrollos y perspectivas. Forum Qualitative Social Research, 8(2). Recuperado de http://www.qualitative-research.net/index.php/fqs/article/view/234/519

Fairclough, Norman. (1995). Media Discourse. Londres: Holder Arnold.

Fernández, Daniel. (2012). Usos metafóricos en el discurso sexual. Reflexiones, 91(2), 141-149.

Fernández, Mauro. (15 de junio del 2009). En el punto: de la ciencia al sexo. San José, Costa Rica. Sistema Nacional de Radio y Televisión, S. A.

Fernández, Mauro. (22 de junio del 2009). En el punto: de la ciencia al sexo. San José, Costa Rica. Sistema Nacional de Radio y Televisión, S. A.

Fernández, Mauro. (27 de julio del 2009). En el punto: de la ciencia al sexo. San José, Costa Rica. Sistema Nacional de Radio y Televisión, S. A.

Figueroa, Patricia. (6 de abril del 2009). Giros en tu vida. San José, Costa Rica. Representaciones Televisivas Repretel, S. A.

Foucault, Michel. (1996). El orden del discurso. Barcelona: Tusquests Editores.

Foucault, Michel. (2000). Tecnologías del yo. Barcelona: Editorial Paidós.

Foucault, Michel. (2001a). Dits et Écrits. (Tomo 3, Le jeu de Michel Foucault). París: Quarto Gallimard.

Foucault, Michel. (2001b). Dits et Écrits. (Tomo 4, Le sujet et le pouvoir). París: Quarto Gallimard. 
Foucault, Michel. (2004). Seguridad, territorio, población. Buenos Aires: Fondo de Cultura Económica.

Foucault, Michel. (2005a). Historia de la sexualidad. La voluntad de saber. (Volumen 1). Buenos Aires: Siglo Veintiuno Editores.

Foucault, Michel. (2005b). La Arqueología del saber. Buenos Aires: Siglo Veintiuno Editores.

Foucault, Michel. (2005c). Un diálogo sobre el poder y otras conversaciones. Madrid: Alianza Editorial.

Foucault, Michel. (2009). Le corps utopique. Les hétérotopies. Clamecy: Éditions Lignes.

Gilman, Sander L. (1994). Disease and Representation. Images of Illness from Madness to AIDS. Nueva York: Cornell University Press.

Halperin. David M. (1997). Saint Foucault. Toward a Gay Hagiography. Nueva York: Oxford University Press.

Jäger, Siegfried. (2007). Discourse and Knowledge: Theoretical and Methodological Aspects of a Critical Discourse and Dispositive Analysis. En: Michael Meyer \& Ruth Wodak (comp.), Critical Discourse Analysis. Londres: Sage Publications.

Jonas, Irène. (2009). Les ouvrages «psi» sur le couple: un nouvel espace de contrôle d'une hétérosexualité normative. En Catherine Deschamps; Laurent Gaissad \& Christelle Taraud (comp.), Hétéros. Discours, lieux, pratiques. París: EPEL.

National Library of Medicine. (2003). Visual Culture and Public Health Posters. Recuperado de: https://www.nlm.nih.gov/exhibition/visualculture/venereal.html

Pérez, Víctor \& Puigdemont, Dolors. (2005). Sexualidad y publicidad. En Ángel Luis Montejo (comp.), Sexualidad Psiquiatría y Cultura. Barcelona: Editorial Glosa.

Preciado, Beatriz. (2002). Manifiesto contra-sexual. Prácticas subversivas de identidad sexual. Madrid: Editorial Ópera Prima.

Preciado, Beatriz. (2008). Testo Junkie. Sexe, drogue et biopolitique. París: Éditions Grasset.

Rich, Adrienne. (1984). Compulsory Heterosexuality and Lesbian Existence. En: Ann Bar Snitow; Christine Stansell \& Sharon Thompson (comp.), Powers of Desire: The Politcs of Sexuality. Londres: Virago. 
Rico-Villademoras Garmoneda, Fernando. (2005). Sexualidad y medios de comunicación. En Ángel Luis Montejo (comp.), Sexualidad Psiquiatría y Cultura. Barcelona: Editorial Glosa.

Rodríguez, Raquel. (2004). Teoría de la Agenda Setting. Aplicación a la enseñanza universitaria, Observatorio Europeo de Tendencias Sociales. Alicenate: A.F. Alaminos.

Rubin, Gayle. (1993). Thinking Sex: Notes for a Radical Theory of the Politics of Sexuality. En Henry Abelove, Michelle Aina \& David M. Halperin (comps.), The Lesbian and Gay Studies Reader. Nueva York: Routledge.

Soares da Silva, Alessandro. (2008). Luta, Resistência e Cidadania. Uma análise psicopolítica dos movimentos e paradas do orgulho LGBT. Curitiba: Juruá Editora.

Tamayo, Richard; Gutiérrez, Eduardo \& Herrera, Eliana. (2002). Rasgos generales del discurso de la radio juvenil sobre la sexualidad y la afectividad. Anagramas. Rumbos y sentidos de la comunicación, 4(8), 171-184.

Van Dijk, Teun. (1990). La noticia como discurso. Comprensión, estructura y producción de la información. Barcelona: Editorial Paidós.

Weeks, Jeffry. (1998). Sexualidad. México D.F.: Editorial Paidós.

Wittig, Monique. (2007). La pensée straigh. París: Éditions Amsterdam.

Ziga, Itziar. (2008). ¿Por qué gritamos las putas? Zehar: revista de Arteleku-ko aldizkaria, (64), 118-123.

Žižek, Slavoj. (1994). The Spectre of Ideology. En Slavoj Žižek (ed.), Mapping Ideology. Nueva York: Verso Books. 